\title{
Toward Social Material Flow Analysis: On the Usefulness of Boundary Objects in Urban Mining Research
}

\author{
Björn Wallsten \\ Linköping University Post Print
}

Tweet

N.B.: When citing this work, cite the original article.

Original Publication:

Björn Wallsten, Toward Social Material Flow Analysis: On the Usefulness of Boundary Objects in Urban Mining Research, 2015, Journal of Industrial Ecology, (19), 5, 742-752. http://dx.doi.org/10.1111/jiec.12361

Copyright: Wiley: No OnlineOpen

http://eu.wiley.com/WileyCDA/Brand/id-35.html

Postprint available at: Linköping University Electronic Press

http://urn.kb.se/resolve?urn=urn:nbn:se:liu:diva-122664 


\section{Toward Social Material Flow Analysis - On the Usefulness of Boundary Objects in Urban Mining Research}

Author: Björn Wallsten*

Published in Journal of Industrial Ecology 19(5) 742-752.

* Corresponding author. Department of Management and Engineering, Environmental Technology and Management, Linköping University, SE58183 Linköping, Sweden. Tel: +4613285625 Email: bjorn.wallsten@liu.se

\section{Summary}

Material flow analysis (MFA) has been an effective tool to identify the scale of physical activity, the allocation of materials across economic sectors for different purposes and to identify inefficiencies in production systems or in urban contexts. However, MFA relies on the invisibilization of the social drivers of those flows to be able to perform its calculations. In many cases therefor, it remains detached from the for example urban processes that underpin them. This becomes a problem when the purpose of research is to design detailed recycling schemes or the like, for which micro-level practice knowledge on how material flows are mediated by human agency is needed.

The aim of this article is to demonstrate how a particular social science approach, namely infrastructure studies (IS), can be combined with MFA to enhance the latter's potential as a decision support tool. To achieve a successful combination between IS and MFA, the object of inquiry must be carefully defined to function as a 'boundary object', that allows academic approaches to work together without the need for consensus (Star \& Griesemer 1989).

This approach is illustrated with a case study example in urban mining research that assesses the hibernating stock of subsurface urban infrastructure in Norrköping, Sweden. It provides an example of how a well-calibrated MFA and a complementary social science approach can provide hands on-advice for private as well as public actors in a local and place-specific context. The article aims to advance the integration of social science and the study of the physical economy to contribute to the emerging social-industrial ecology.

Keywords: urban mining; material flow analysis (MFA); science, technology and society (STS); boundary objects; hibernating stocks; infrastructure 


\section{Introduction}

Chertow (2000) rightfully claims that material flow analysis (MFA) studies most often operate at regional or global scales. Following on from this, it is no surprise that the impact of such studies so far has been most apparent in high-level policy that uses aggregated data. MFA researchers have supported policy makers in formulating goals and targets in relation to the resource scarcity debate. Taking minerals as an example, the strategic documents for raw materials that the EU at large and several European countries have developed or are developing, are based on the same kind of stocks and flows perspective that can be found in MFA studies. Increased target rates for recycling are a societal goal in these strategies, which is also the case with the EU waste hierarchy (EU 2008). The existence of these strategic documents indicates that the perspectives that MFA is based upon have been influential, and that the method's applicability to higher-level decision-making cannot be ignored.

If however, and as Graedel and Allenby (2002 p. 301-302) point out, the desired outcome of MFA studies is to further inform the design of recycling schemes, then MFA must be recalibrated to aid the translation of policy targets and goals to local domains for practical implementation. Research has shown that household waste behavior is pivotal when suggesting appropriate recycling schemes (Bulkeley and Gregson 2009) and for this to be achieved, it is important to integrate the flows and stocks' societal dimension into the MFA. Significantly, the social context of material flows studied is often neglected in the analysis, a limitation that has been recognized by researchers in the industrial ecology field (cf. Anderberg 1998; Newman 1999; Barles 2010; Minx et al. 2011), as well as outsiders (cf. Gandy 2004; Swyngedouw 2006; Monstadt 2009; Castán Broto et al. 2012; Hodson et al. 2012).

In this article, I argue that MFA needs to acknowledge and overcome this limitation. To further develop the quantitative assessment with qualitative explanations on how, when and by whom material flows are sustained, MFA must from the outset be rigged to fit with a complementary social science research approach. I exemplify my argument with a description of an already-conducted case study of the hibernating stocks of subsurface urban infrastructure in Norrköping, Sweden (Wallsten 2013). Hibernating stocks is a concept that originates from within the MFA community and is used to classify materials that have been taken out of use but not yet entered the waste sector (Bergbäck and Lohm 1997). In the case of subsurface urban infrastructure, hibernating stocks consist of cables and pipes that remain underneath city streets after having been disconnected. 


\subsection{Aim}

The aim of this article is to show how a particular field of social science, namely infrastructure studies (IS), can be combined with MFA and how such a combination can enhance urban mining research and practice. By describing the approach and results from the example case study, I stress the importance of delimiting and carefully situating the object of inquiry to function as a "boundary object" (Star and Griesemer 1989; Star 1999, 2010) at the core of the research design. Such an object allows different academic approaches to "work together without consensus" (Star 2010 p. 602), which in this case implies a research design that includes both quantitative (MFA) and qualitative (IS) assessments. While such a combination is not news in and of itself, the few cases where MFA has been complemented with social science approaches were primarily based on quantitative modeling (cf. Binder 2007) or were mere suggestions (cf. Hodson et al. 2012). In terms of actual completed research, combinations of MFA and qualitative social sciences have been lacking, and so consequently, the two approaches of MFA and IS had never been combined until the case study exemplified herein was conducted. The purpose of showing how the case study research was carried out is to provide an example of how a research design consisting of a well-calibrated MFA and complementary social science approach can provide hands-on advice in a local and place-specific context while scientifically advancing the two approaches in the process. The contribution is thus both practice-related and methodological.

\subsection{Article outline}

In the following, the scientific merits of MFA and IS are described with the purpose of highlighting their common ground as well as discrepancies between them. A previous research section on hibernating stocks of urban infrastructure is also presented for each of the respective approaches for the sake of later comparison with the results achieved in the example case study (parts 2 and 3). This is followed by an introduction to what boundary objects are and how they are beneficial in mixed-methods approaches (part 4). Then I introduce the topic of the example case study and its research design, and address how this differed from how MFA and IS studies are traditionally carried out. In the last section before the conclusions, I present the results of the example case study, discuss how these relate to previously conducted MFA and IS research, and consider why they could not have been achieved without the particular research design. 


\section{No Flow Left Behind: the Lynchpins of Material Flow Analysis}

Material flow analysis gathers its epistemological underpinning from urban metabolism, an analytical framework that focuses on the material composition of cities and how cities rely on and enable different kinds of material and energy flows. Within this framework, the city is divided into two separate spheres: the urban biosphere consisting of all the materials that people and other urban organisms consume, and the buildings and infrastructure of the urban fabric (cf. Douglas 1983; Douglas and Lawson in Ayres and Ayres 2002). The urban process is thus first and foremost understood as consisting of material exchanges, in which renewal of the urban fabric results in material wastes that are used to level original building sites for new construction. Cities thus rise over the residues of past structures, in a way that over time creates an "urban deposit" of material residues (Wilburn and Goonan 1998). The study of urban metabolism is often done with one of the following four methodological approaches, which are all used for quantitative assessments but fulfill different purposes: Material Flow Analysis (MFA), Substance Flow Analysis (SFA), Energy Flow Analysis (EFA) and Environmental Footprinting (Barles 2010 p. 444). Since materials were the primary concern of the Norrköping case study, MFA was chosen as the relevant approach.

MFA is an accounting exercise aimed at quantifying material entities such as urban fabric on a superficial, summary level in a delimited area (Kennedy et al. 2011). MFA relies on reducing the complexities of reality into a simplified matter of input, output and transfer characteristics (Bringezu and Moriguchi in Ayres and Ayres 2002; Brunner and Rechberger 2004). In practice, there is a great deal of methodological variety in how MFA is performed (Chen and Graedel 2012) ${ }^{1}$. The two predominant approaches found in handbooks are top-down MFA and bottom-up MFA (cf. Brunner and Rechberger 2004; Graedel and Allenby 2010), which in practice are often combined for triangulation purposes (cf. Zeltner et al. 1999). Top-down MFA relies on flowcharts with boxes and arrows representing the stocks and flows of the material chosen for the assessment. Bottom-up MFA is instead based on product data and inventories and thanks to it being possible to add a spatial component to its estimations we chose it for the case study. The important accounting device

\footnotetext{
${ }^{1}$ Since the 1990s, two major strands of analyses have emerged: material flow accounting (or economy-wide MFA), that targets the overall material metabolism of societies, and MFA/SFA approaches that focus on individual flows of materials and chemicals through a variety of different systems (Bringezu et al. 1997). Among the latter, there is a need to differentiate between static and dynamic studies. Static studies are those that refer to flow characteristics at a given moment in time (e.g. Van der Voet et al. 2000), while dynamic ones simulate the material or substance flows over time with the ambition to do forecasts or scenario analyses (e.g. Müller 2009). There are also studies that focus solely on stocks and exclude flows (e.g. Takahashi et al. 2009). An alternative approach to MFA is provided by ecological or environmental footprinting, which is based on the translation of material flows into the amount of land area that is required to sustain them (Castán Broto et al. 2012).
} 
for bottom-up MFA studies is the extensive inventories of all entities that contain the material chosen for the assessment. In the case of metals, inventories tend to include entities such as buildings, infrastructure, cars and electronic gadgets (see Table 1). The material contents of the determined entities are found using product data which are then either multiplied by the actual number of entities in the area of assessment (if known) or by an average number of entities per capita that exist for a reference area comparable to the one under scrutiny. Census data often form the basis of bottom-up estimations (Graedel and Allenby $2010 \mathrm{p}$. 245), and the number of buildings, cars, electric grid components etc. can sometimes even be determined by using GIS-based statistics, to arrive at total stock estimates and their location (cf. van Beers and Graedel 2007).

\begin{tabular}{llc} 
Principal copper stocks in New Haven & & \\
\hline & $\mathrm{kg} / \mathrm{c}$ & Cumulative sum \\
\hline Power generation and transmission & 42 & 42 \\
Plumbing & 28 & 70 \\
Wiring & 25 & 95 \\
Cars & 8 & 103 \\
A/C and equipment & 12 & 115 \\
Ships & 7 & 122 \\
Telecommunications & 5 & 127 \\
House E\&E & 6 & 133 \\
House white & 3 & 136 \\
Commercial E\&E & 1 & 137 \\
Industrial machinery & 3 & 140 \\
Trucks and buses & 3 & 143 \\
Architectural & 1 & 144
\end{tabular}

Table 1. A typical inventory of stocks in a bottom-up MFA, where the stock calculations are based on their kg/capita (c) content. (Reproduced from Drakonakis et al. 2007).

In the following, I use cars as an example to explain the process of bottomup MFA. As individual unified objects, cars are too "shallow" to play a significant part in bottom-up MFA assessments. Instead, cars are reduced to composites of their fundamental elements and understood as aggregates of material measured in mass units/car. The approach then leaps from one reductionist stance to another, as the mass unit per car is multiplied by the number of cars in the area of concern to arrive at total quantities. The important thing for MFA is thus that cars are not treated as individual unified objects that are bought, used, sold and circulated by people in social processes such as car sales, auctions, scrapyards etc., but that they are decontextualized to first and foremost contribute to stocks and flows of materials through their internal composition qualities.

The primary motive for users to engage with objects is based on their capability to provide a desirable function and not how they constitute material stocks and flows. In this respect, the bottom-up MFA worldview is 
biased and might result in claims that the average citizen moves around in steel is roughly equivalent to "the weight of a car, although in reality, each person has less than a whole car and the rest is made up by other vehicles" (Alwood and Cullen 2012 p. 61). While the underlying numbers behind such a quote might be useful for the formulation of recycling targets and high-level policy goals, MFA's omission of social factors become troublesome when it comes to informing the design of detailed recycling schemes. This is because as a car owner you engage with your vehicle as an indivisible object, which is something that bottom-up MFA studies do not acknowledge, since it relies on hiding the socially entangled mechanisms by which urban flows of the material in question are sustained.

\subsection{Previous MFA Research Related to Hibernating Stocks of Infrastructure}

Previous MFA research reveals that limited data are available on hibernating stocks. The computational difficulties inflicted by the lack of adequate data, and that hibernating stocks are empirically difficult to determine because of their dependence of consumer behavior patterns (Kapur and Graedel 2006), mean that "amazingly little" is known about where and how large hibernating stocks actually are (Brunner 2004 p. 5). Hence, hibernating stocks are most often estimated based on the differences between the in-flow and out-flow rates of materials, adjusted for materials found in in-use stock. The few recent MFA research overviews that explicitly mention hibernating stocks of urban infrastructure do not describe them in much detail (Alwood and Cullen 2012 p. 267) and regard it as highly unlikely that they would ever be recovered (Graedel 2011 p. 48).

The case study presented here of Norrköping (Sweden) quantifies and spatially assesses the hibernating metal stocks for copper, aluminium and steel found in the city's subsurface infrastructure. Societal reliance on these three metals is highly significant; they are consequently characterized by good data availability and have often been the focus of previous MFA studies. Studies particularly interested in urban stocks of these three metals have covered fourteen stocks in nine different cities (Hendricks et al. 2000; Bergbäck et al. 2001; Sörme et al. 2001; Tanikawa et al. 2002; van Beers and Graedel 2003; Tanikawa et al. 2004; Drakonakis et al. 2007; van Beers and Graedel 2007; Tanikawa et al. 2009a; Tanikawa et al. 2009b), and while some of these studies used GIS software to end up with spatially informed results (e.g. van Beers and Graedel 2003, 2007), none of them focused on hibernating stocks, their size or spatial location. MFA studies prior to the Norrköping study seem to have lacked the necessary information sources to address hibernating stocks. 


\section{Embracing the Sociotechnical Messiness: the Lynchpins of Infrastructure Studies}

Infrastructure studies (IS) gathers its epistemological underpinnings from the larger academic field of Science and Technology Studies, and understand cities and their infrastructure as sociotechnical artifacts (see Graham and Marvin 2001 pp. 7-35). From such a perspective, everything that seems to be purely technical is also social, and the social and technical aspects of a sociotechnical phenomenon should therefore be approached as an integrated whole (e.g. Sismondo 2004).

A sociotechnical understanding of infrastructure systems relies on incorporating their context of politics, organizations, regulations etc. (Hughes 1983). The people responsible for the management of an infrastructure system's development must, as a consequence, be understood as heterogeneous: i.e. work not only with technology as such, "but on and through people, texts, devices, city councils, architectures, economics and all the rest" (Law 1991 p. 9).

From a sociotechnical perspective, urban infrastructure systems are understood as socially embedded in their urban context where a large set of actors can shape and become affected by their development (Tarr and Dupuy 1988; Aibar and Bijker 1997). The sociotechnical perspective allows the researcher to "embrace the messiness of contemporary cities" and disclose the processes that explicitly relate urban citizens to their material surroundings (Guy and Karvonen 2012 p. 121). This is important since urban fabric displays a certain inherent obduracy that resists and intervenes in all transformational urban activities (Hommels 2005).

From an IS perspective, urban transformations are understood to be the result of "interrelated dynamics of the landscape of buildings and the landscape of networks" (Gullberg and Kaijser 2004 p. 15). Coordination mechanisms between different human actors are needed to create these changes in the urban fabric, and buildings and infrastructure systems are necessary components to understand this development (Gullberg and Kaijser 2004 p. 34).

\subsection{Previous IS Research Related to Hibernating Stocks}

The concept of infrastructure "cold spots" has come the closest, in the field of infrastructure studies research, to explicitly addressing disconnected parts of urban infrastructure (Guy et al. 1997; Moss 2003, 2008; Naumann and Bernt 2009). They are defined as "parts of infrastructure systems where demand is weak and/or declining" (Moss 2008 p. 438). The 
underlying dynamics of cold spots have been in particular focus in IS research. For example, it has been shown that cold spots occur as a result of the underutilization of system services that follows from factory shutdowns in industrial areas (Moss 2003) or because of urban shrinkage processes (Moss 2008; Naumann and Bernt 2009). However, cold spots are never distinguished in terms of size or in spatial pattern terms, and as they signify locations with weak or declining demand for infrastructure services, they do not consider accumulated amounts of disconnected parts of infrastructure.

An early criticism articulated toward infrastructure studies was the field's narrow orientation toward development-biased descriptions of technological progress (Bijker and Law 1992). This argument has been backed up with more recent remarks on how research has too often been focused on the extend-and-supply logic of system flows (Moss 2008 p. 439) and the managers or so-called system builders responsible for these extensions (cf. Law 1991 p. 12; Graham and Marvin 2001 p. 183). This deficiency is likely related to why relatively little is known about infrastructure system decline in general (Gandy 2005), and why we are seldom if ever served explicit accounts on how infrastructure systems are discontinued or un-made (Weber and Salehabadi 2012). Given these observations, it is perhaps not surprising that disused infrastructure and hibernating stocks have thus far been neglected as a research topic within IS.

\section{On the Usefulness of Boundary Objects}

MFA and IS scholars share an interest in the material configuration of cities but they operate in different conceptual territories (cf. Otter 2010; Brunner and Rechberger 2004). MFA scholars understand the city as a purely biophysical entity in which material flows over time accumulate into urban fabric. Therefore, they purposely simplify the urban fabric into a device for accounting for material accumulation, while its existence as a result of actors engaged in sociotechnical processes is left outside of the analysis. This is, on the other hand, the explicit focus in IS in which the process behind the particular sociotechnical configuration of the urban fabric is emphasized. IS scholars study and give actors, politics, coordinating mechanisms and so on a central position in their research design.

But how then can the diverse perspectives of MFA and IS find a "trading zone" in which both can benefit? I suggest here that a research design that wants to achieve this must delimit its object of inquiry so that it functions as a boundary object between the approaches. Star and Griesemer 
introduced boundary objects (1989) to define certain objects that are adaptable to different scientific viewpoints. And since they can "inhabit several intersecting social worlds" and "satisfy the informational requirements of each of them", "their structure is common enough to more than one world to make them recognizable" (Star and Griesemer 1989 p. 393), and they can adhere to several demands simultaneously (Star and Griesemer 1989 p. 412).

The merits of boundary objects suggest their usefulness in a case study assessment of hibernating stocks of urban infrastructure since they can be positioned to form a common boundary between the worlds of MFA and IS. However, such positioning comes with a set of requirements for how the boundary object is delimited, as it should both enable the decontextualized quantitative assessment of an MFA and allow for recontextualization in qualitative process terms from the IS perspective. To achieve this, I argue that the spatial and material scope must be made significantly smaller compared to traditional MFAs to keep the assessment local and with fewer included material entities. While the scope must of course remain detailed enough to allow for relevant estimations of urban metal stocks, it should also allow the qualitatively-interested IS researcher to find suitable interviewees involved in social processes related to the same stock. My argument is thus not that the disparate approaches of MFA and IS must merge into a consensus on how the object of inquiry should preferably be understood. Rather, they must be set to cooperate and create a mutual modus operandi that makes use of their internal diversities for the benefit of both.

\subsection{What can be gained from such a research design?}

To create a successful translation of recycling targets into local implementation, knowledge concerning how much material can potentially be recycled is essential, but so is knowledge about when, where and through the help of whom recycling occurs (Lane 2014). That MFA needs a good fit with an accompanying social science assessment is supported by the findings of Bulkeley and Gregson (2009), who claim that social scientific knowledge of household behavior is pivotal when suggesting appropriate recycling schemes for household waste. Similarly, IS needs quantitative MFA data to prompt hibernating stocks as a research topic: if the amount of disconnected cables and pipes was not known, it could be easily be disregarded as unworthy of social science scrutiny.

With an underlying agenda of wanting to inform the design of detailed recycling schemes, I argue that MFA must overcome some of its reductionist ways of aggregating numbers and general beliefs in average 
means and generalizations. Such arithmetic operations run the risk of distancing the material objects from their socially embedded and locally contingent realities by turning them into computable numbers that are irrelevant for social science methods. In many MFA examples, data might either be collected at a scale maladjusted to local recycling schemes (i.e. international trade numbers) or constructed in a way that obfuscates the material objects in relation to what they mean to relevant stakeholders (e.g. the calculated averages of kilograms of car material per capita). Arithmetic operations are key to the MFA analysis, but they need to be framed to create a match with a complementary social science approach of choice: if you are going to calculate the size of stocks, you should choose a spatial and material scope that is adequate in relation to informants with relevant knowledge of the processes in which the stocks are created. Many stress the need for interdisciplinary approaches (cf. Nakamura and Sato 2011; Castán Broto et al. 2012; Hodson et al. 2012), a message that is not new to the MFA discipline. Examples of how interdisciplinarity can be achieved are, however, much more rare and so the next section describes a case study that engaged explicitly with that in concrete research practice (Wallsten 2013).

\section{The Example Case Study: Urban Infrastructure Mining in Norrköping, Sweden}

The example case study involves urban mining research, i.e. secondary recovery of materials found in the urban built environment (cf. Baccini and Brunner 1991). The particular stock in focus was the urban infrastructure of the Swedish city of Norrköping and its contents of copper, aluminium and steel that can be found in, for example, the grids for power distribution, district heating and telecommunications. Particular attention was given to the hibernating stocks of these metals (Bergbäck and Lohm 1997), i.e. the metals in cables and pipes that are not in use but remain in their subsurface location. In theory, these are immediately available for recycling and thus of particular interest from an urban mining perspective.

The case study was done with the purpose of highlighting the hibernating stocks' potential as an alternative resource reserve and to find out how they come into existence in social processes. The research design thus had to support both the stocks and flows perspective and quantitative assessment of an MFA analysis (Wallsten et al. 2013a) and allow for recontextualization in qualitative process terms with a sociotechnically informed perspective (Wallsten et al. 2013b). Together, these two refereed articles constituted the case study (see Wallsten 2013). 


\subsection{Choosing a Boundary Object: The Research Design of the Example Case Study}

In line with how IS assessments are often structured as case studies and thus begin by carefully delimiting the object of inquiry (Guy and Karvonen 2012), the setup of the example case study in this article started with deciding the object of inquiry as the urban infrastructure in Norrköping. This purposely resulted in a limited number of stakeholders to interview and allowed for the inclusion of ownership and management of the different systems in the analysis. The applied infrastructure studies method was furthermore inspired by what Bowker (1994, quoted in Star 1999) has termed an "infrastructure inversion". Such an inversion relies on intentionally foregrounding the backstage elements of work practice to reveal hidden characteristics of the case at hand. Influenced by Graham and Thrift (2007), maintenance and repair workers were given a pivotal position in the study. Since they actually see and touch the disconnected infrastructure before it is reburied, they became our "chief means of seeing and understanding the world" (Graham and Thrift 2007 p. 5) through their everyday involvement in cable and pipe disconnection processes. They have vital knowledge on the societal arrangements that allow hibernating stocks of infrastructure to accumulate.

Contrary to how most MFA studies are carried out, the materials for the MFA assessment part of the case study were taken into consideration after (not before) the urban infrastructure in Norrköping was decided as the object of inquiry. The metals included in the case study and the inventory of objects were thus determined as a consequence of the chosen object of inquiry and not vice versa. In a sense, the case study was predominantly set to make a good fit with IS, thereby resulting in implications for how the MFA could be performed, however without negotiating MFA's quantitative assessment merits. In reverse, the IS part of the case study had to shift away from only focusing on the system providers and instead also rely on an often-neglected group of informants, the maintenance and repair workers. Creating a common ground for the respective analytical qualities of MFA and IS was key to achieving the boundary object-reliant research design.

Furthermore, circling in on "one" object, hibernating stocks of urban infrastructure, deliberately resulted in a significant delimitation of the scope of MFA that protected it from becoming lost in aggregation or transformed into per capita measurements. Instead, it allowed for timeconsuming spatial data collection. Municipal statistics and historical maps dating back to the 1850 s were used for systems disconnected in their entirety, while image files and GIS data were used for still-operating systems. With the exception of information on metal content in different 
cable types, the limited scope allowed the use of data that corresponded with the local context. Most of the data used thus stem from sources that describe conditions within the boundaries of the case study. In terms of reliability, this is a strength in comparison to MFA studies that rely on whatever data could be found regardless of geographical origin. Furthermore, the scope could be kept local and in line with the social organization of these stocks.

For the IS part of the case study, the focus on hibernating stocks of urban infrastructure resulted in an adequate number of respondents easily being found. System owners as well as subcontractors were selected to involve both sides of the procurement contracts regulating the outsourced maintenance and repair services, and a connection between the sociotechnical functioning of infrastructure systems and their dependence on contract formulations was thus established with the systems' enablers as mediators of material flows. Urban processes were consequently found to be intimately connected to the accumulation of hibernating stocks of infrastructure, connections that were previously undetected by IS research.

\subsection{Achievements of the Research Design: The Results of the Case Study}

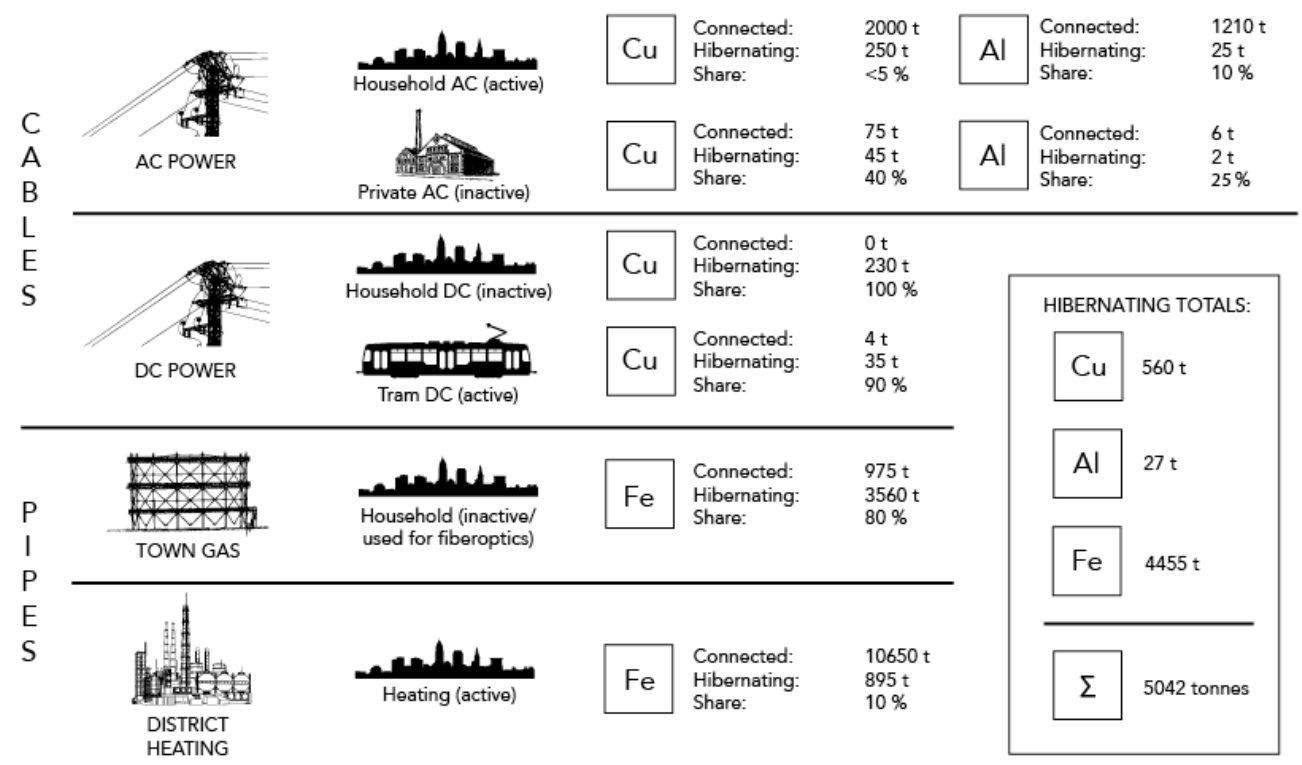

Table 2. The inventory of in-use as well as hibernating metal stocks found in six urban infrastructure systems of Norrköping (Reproduced from Wallsten et al. 2013a). The level of detail was achieved by delimiting the MFA to only account one category of metallic entities in the chosen geographical area (cf. Table 1).

The delimited object of inquiry enabled more detailed scrutiny and allowed us to calculate both the in-use and hibernating stocks of six different infrastructure systems (see Table 2). In comparison with the total stock estimates in previous studies (see Table 1), this resulted not only in more precise information about several infrastructure systems, but also added a 
completely new study dimension insofar as we could compare the in-use metal amounts with never before estimated hibernating infrastructure stocks. In sum, we found 5000 tonnes of infrastructure metals hibernating underneath Norrköping's streets, divided between $88 \%$ steel, $11 \%$ of copper and $1 \%$ of aluminium (see Table 2). For steel and copper, this equaled a fifth of the total stocks of these metals. Furthermore, we could determine the owners of the hibernating stocks (which is non-decipherable in the study presented in Table 1, for example) and were thereby able to conclude that the (dis-)incentives for urban infrastructure mining of copper were equally shared between the municipality and the private company power supplier in Norrköping, since their stocks were similar in size.

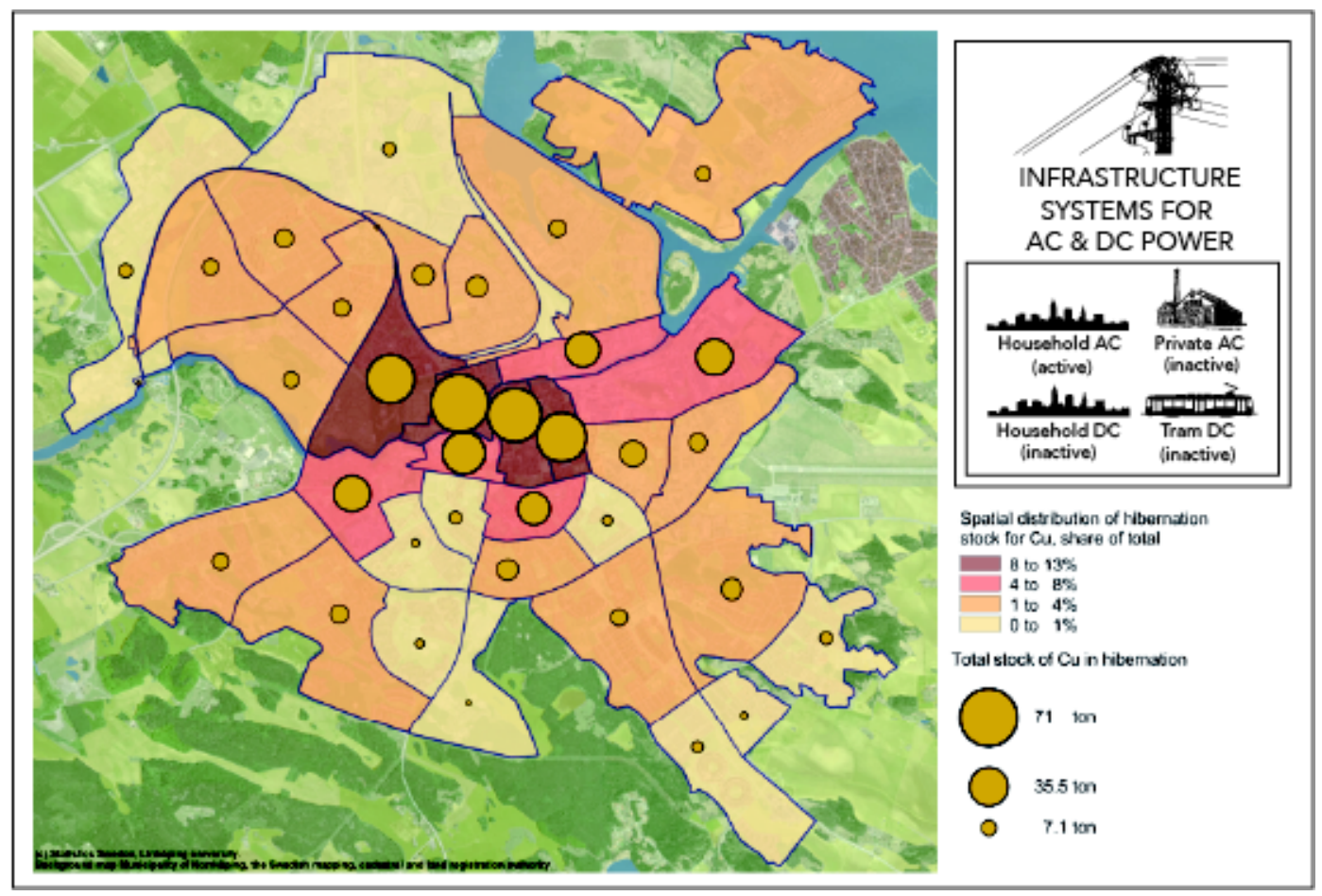

Map \#1. The hibernating stocks of copper in the urban infrastructure of Norrköping, Sweden (Reproduced from Wallsten, 2013), comparable to previous GIS-based MFA-studies that estimate only the size and spatial distribution of in-use stocks (cf. van Beers and Graedel 2007). The tendency of centrality is clearly displayed.

We not only determined the size and ownership of the hibernating stocks, but were also able to engage in a spatial analysis of how they were dispersed across different city districts (see Map 1). Previous maps of urban metal stocks (e.g. van Beers and Graedel 2007) use a similar spatial analysis, but there are two noteworthy differences. First, their maps only display in-use stocks of metals, and second, they deal with aggregated sums of all the metals estimated in all metal-containing entities within the given geographical area. Thanks to our delimited focus and the level of detail provided by the large amount of collected local data (historical as well as contemporary), our results point to where directly available parts of a 
specific hibernating stock tend to be located, which brings our study closer to the realization of urban mining initiatives. The results disclosed a tendency of centrality for all three hibernating metal stocks, and city district age could thus be determined as a key factor. We could furthermore conclude that industrial areas were likelier to contain hibernating infrastructure than residential ones, indicating such areas as suitable for urban infrastructure mining initiatives.

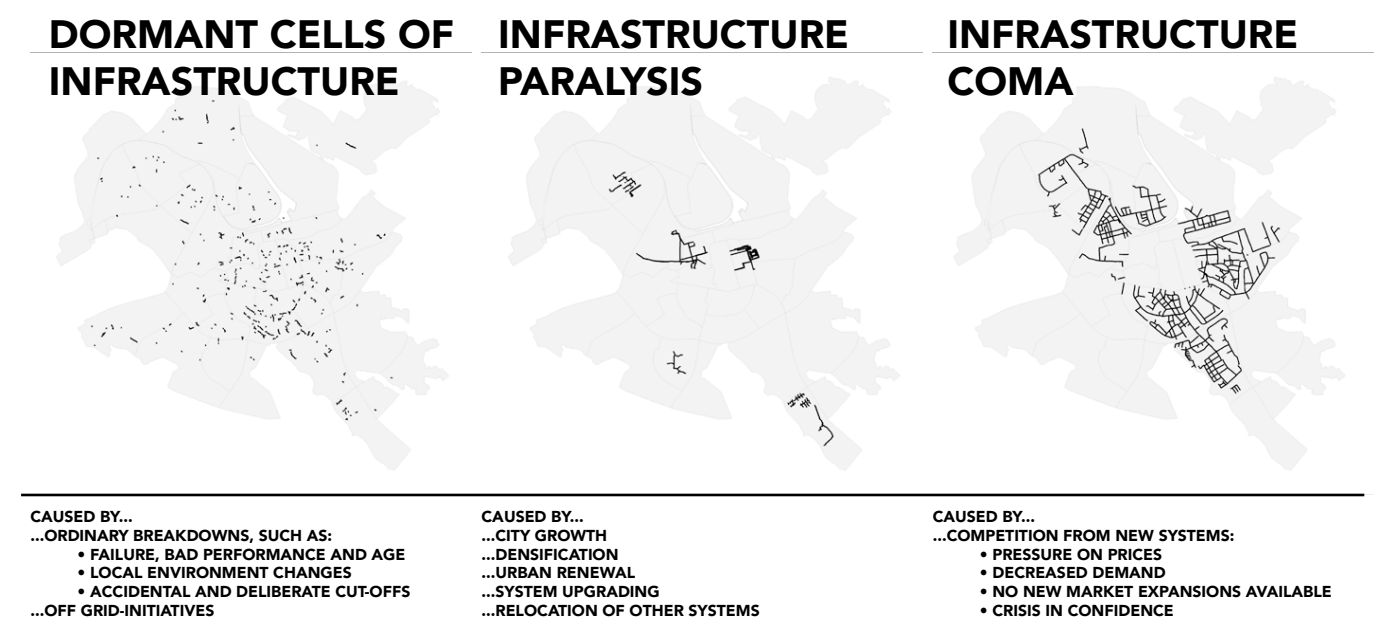

Map \#2. Three different infrastructure 'frozen spots' distinguishable in size and spatial distribution and each with their own underlying "disconnect and leave behind"-dynamics (Reproduced from Wallsten et al. 2013b). From left to right, they relate to everyday work with maintenance and repair (dormant cells), urban re-development projects (paralysis) and system obsolescence (coma). To arrive at these results, the research design did not allow for a decontextualized MFA but instead included a complementary infrastructure studies-approach.

In the GIS data used to compile the hibernating stocks map above, we observed three different patterns of hibernating urban infrastructure that must, tentatively, be correlated to infrastructure management practices. These hibernation patterns were observed in more than one infrastructure system, suggesting them to be generalizable phenomena, and were verified in the interviews with the maintenance and repair workers. Thus, we suggested "frozen spots" of infrastructure in three different spatial patterns and sizes, as a theoretical expansion in relation to previous IS research on infrastructure cold spots. Each of these types of frozen spots were furthermore determined as reliant on their own sets of dynamics of ceased or non-existent demand (see Map \#2).

The final major contribution enabled by the research design was the delineation of a "disconnect and leave behind" logic by which the actors involved handle the continuous process of incremental decline in urban infrastructure systems. Being a kind of inverse of the often studied "extend and supply" logic (as observed by Moss 2008), this logic also explained how hibernating stocks come into existence. The maintenance and repair crews' role as key informants cannot be stressed enough here, as they established 
the sociotechnical connection between the hibernating stocks and the daily operations of infrastructure provision in Norrköping. On many occasions, alterations in the contracts that regulate infrastructure provision (i.e. between system owners and different subcontractors) were mentioned as a possibility to encourage further infrastructure recycling. The importance of not only emphasizing the system providers' perspective in an IS assessment, was thus another lesson learned from the case study.

\subsection{Tentative Suggestions for Future Urban Infrastructure Mining}

In summary, the case study allowed the combination of quantitative knowledge on the amounts and spatial dispersion of metals, and qualitative knowledge of the social processes by which they accumulate. The hibernation logic of urban infrastructure provision outlined, connected the MFA results to social processes at the level of human practices and waste creation. Through this combination of different epistemological claims, we could suggest different starting points for where and how to start to sketch out future recycling schemes. Whereas large-scale recycling of obsolete infrastructure systems seems unrealistic under the current conditions, both from economic and managerial points of view, there appear to be possibilities to engage in urban mining in conjunction with everyday infrastructure maintenance and repair operations as well as whenever larger city redevelopment projects occur. In even more concrete terms, suggestions can be made that the contracts by which daily infrastructure maintenance are procured should also include requirements for recovery of replaced infrastructure parts. Larger city redevelopment projects might, according to the same line of thinking, be accompanied by plans for how to recover existing infrastructure. On a more strategic level, the resource management of urban infrastructure in Norrköping would benefit if it was ensured that relevant recycling processes were followed whenever the streetscape is dug up for any purpose.

\section{Concluding remarks}

Delimiting the scope of an environmental assessment tool to create a better match with a complementary social science approach as suggested in this article, is notably different from common conceptual suggestions that suggest extending a quantitative methodological tool to also include social aspects (cf. Newman 1999; Binder 2007; Hodson et al. 2012; Ramaswami et al. 2012). However, if the ambition is to get closer to human actions as well as processes, then a delimited object of inquiry and a narrower spatial as well as material scope in comparison to conventional approaches is 
justified. While conventional MFAs are most often used to paint the whole picture of a geographical scale or area of study, the limited scope of the case study presented here meant that the object of inquiry was not lost in flowcharts or inventories. The MFA can in such cases instead first provide reliable local estimates of how much the hibernating stocks weigh and where they are located, and then hand the estimates over to the sociotechnical assessment. This is what is gained in MFA terms here: results that instead of generalizing data to also account for other scales and levels of inquiry, can inform the local context and the different sociotechnical processes that move materials around there. In IS terms, what was gained by teaming up with a complementary MFA-approach was knowledge about a previously unknown sociotechnical system dynamic of "disconnect and leave behind". Entangled in the daily work of the maintenance and repair crews, this dynamic continuously accumulates surplus parts in a subsurface urban sink and is thereby the inverted complement of the often studied "extend and supply" dynamic of infrastructure systems.

The case study showed that for an MFA to remain connected to the local contexts of the stocks and flows it aims to assess, it must not lose the "where", "when" and "by whom" questions by trying to say too much in terms of summated metal stocks (cf. Table \#1 with Table \#2). In the case study, it was determined where the hibernating stocks are: according to different hibernation patterns and predominantly in central (and industrial) areas (see Map \#1), when they accumulate: in relation to system obsolescence, larger development projects and maintenance and repair (see Map\#2), and by whom this is ensured: the actors involved in the sociotechnical processes regulated in procurement contracts of infrastructure provision (system managers, maintenance subcontractors and so on).

The major argument derived from this work is that engaging in crossdisciplinary research design based around boundary objects may suggest a productive way forward for more implementation-relevant MFA research. While there is still a lot of ground left to be covered, this article has not only presented a conceptual suggestion but also showed an example of how this could be engaged with in practice. The two applied research approaches had to make compromises and/or extensions to adapt to the combined research design, but they did not lose their respective core qualities. Thus, this article suggests that future studies of urban material stocks and flows should concern not only what social science perspectives might add to MFA, but also what MFA research might add to the social sciences. 


\section{Acknowledgements}

Financial support from the Swedish Research Council for Environment, Agricultural Sciences and Spatial Planning, FORMAS, and the Swedish Innovation Agency, VINNOVA, is gratefully acknowledged. The manuscript was copyedited by Karin Hosking. 


\section{References}

Aibar, E. and W. Bijker. 1997 Constructing a City: The Cerdà Plan for the Extension of Barcelona. Science, Technology, \& Human Values 22(1): 330 .

Alwood, J.M. and J.M. Cullen. 2012 Sustainable Materials - With Both Eyes Open. UIT Cambridge.

Anderberg, S. 1998. Industrial metabolism and the linkages between economics, ethics and the environment. Ecological Economics 24: 311-320.

Ayres, R. and L.W. Ayres (eds.). 2002. A Handbook of Industrial Ecology. Cheltenham, UK: Edward Elgar Publishing.

Baccini, P. and P. Brunner. 1991. Metabolism of the Anthroposphere. Berlin: Springer-Verlag.

Barles, S. 2010. Society, energy and materials: the contribution of urban metabolism studies to sustainable urban development issues. Journal of Environmental Planning and Management 53(4): 439-455.

Bergbäck, B. and U. Lohm. 1997. Metals in Society. In Brune, D., D.V. Chapman, M.D. Gwynne, and J.M. Pacyna (eds.). The Global Environment - Science, Technology and Management. Oslo: Scandinavian Science Publisher.

Bergbäck, B., K. Johansson and U. Mohlander. 2001. Urban metal flows - A case study of Stockholm. Water, air \& soil pollution 1: 3-24.

Bijker, W. and J. Law. 1992. General Introduction. In Bijker, W. and J. Law (eds.). Shaping Technology/Building Society: Studies in Sociotechnical Change. Cambridge, MA: MIT Press.

Binder, C. 2007. From material flow analysis to material flow management Part I: social sciences modeling approaches coupled to MFA. Journal of Cleaner Production 15(17): 1596-1604.

Bowker, G. 1994. Science on the Run: Information Management and Industrial Geophysics at Schlumberger 1920-1940. Cambridge, MA: MIT Press.

Bringezu, S., S. Moll, M. Fischer-Kowalski, R. Kleijn, and V. Palm. 1997. Regional and national material flow accounting, "From Paradigm to Practice of Sustainability". Proceedings of the 1st ConAccount workshop, Leiden 21-23 January, 1997. Wuppertal Specials no. 4. Wuppertal, Germany: Wuppertal Institute. 
Bringezu, S. and Y. Moriguchi. 2002. Material flow analysis. In Ayres, R. and L.W. Ayres (eds.). A Handbook of Industrial Ecology. Brookfield: Edward Elgar.

Brunner, P. 2004. Materials Flow Analysis and the Ultimate Sink. Journal of Industrial Ecology 8(3): 4-7.

Brunner, P. and H. Rechberger. 2004. Practical Handbook of Material Flow Analysis. Boca Raton: Lewis Publishers.

Bulkeley, H. and N. Gregson. 2009. Crossing the threshold: municipal waste policy and household waste creation. Environment and Planning A 41: 929-945.

Castán Broto, V., A. Allen and E. Rapoport. 2012. Interdisciplinary Perspectives on Urban Metabolism. Journal of Industrial Ecology 16(6): 851-861.

Chen, W. and T.E. Graedel. 2012. Anthropogenic Cycles of the Elements: A Critical Review. Environmental Science \& Technology 46: 8574-8586.

Chertow, M. 2000. Industrial Symbiosis: Literature and Taxonomy. Annual Review of Energy and the Environment 25: 313-337.

Douglas, I. 1983. The Urban Environment. London: Arnold.

Douglas, I. and N. Lawson. 2002. Material flows due to mining and urbanization. In Ayres, R., and L.W. Ayres (eds.). A Handbook of Industrial Ecology. Brookfield: Edward Elgar.

Drakonakis, K., K. Rostkowski, J. Rauch, T.E. Graedel and R.B. Gordon. 2007. Metal Capital Sustaining a North American City: Iron and Copper in New Haven, CT. Resources, Conservation and Recycling 49: 406-420.

EU (European Union). 2008. Directive 2008/98/EC. ec.europa.eu/environment/waste/framework. Accessed March 2014.

Gandy, M. 2004. Rethinking urban metabolism: Water, space and the modern city. City 8(3): 363-379.

Gandy, M. 2005. Cyborg Urbanization: Complextiy and Monstrosity in the Contemporary City. International Journal of Urban and Regional Research 29(1): 26-49.

Graedel, T.E. 2011. The Prospects for Urban Mining. The Bridge 43-50.

Graedel, T.E. and B.R. Allenby. 2010. Industrial Ecology and Sustainable Engineering. Upper Saddle River, NJ: Pearson/Prentice Hall. 
Graham, S. and S. Marvin. 2001. Splintering Urbanism: Networked infrastructures, technological mobilities and the urban condition. London/New York: Routledge.

Graham, S. and N. Thrift. 2007. Out of Order: Understanding Repair and Maintenance. Theory, Culture \& Society 24(3): 1-25.

Gullberg, A. and A. Kaijser. 2004. City-building regimes in post-war Stockholm. Journal of Urban Technology 11(2): 13-39.

Guy, S., S. Graham and S. Marvin. 1997. Splintering networks: cities and technical networks in 1990s Britain. Urban Studies 34(2): 191-216.

Guy, S. and A. Karvonen. 2012. Using sociotechnical methods: Researching human-technological dynamics in the city. In Mason, J. and A. Dale (eds.). Understanding Social Research: Thinking Creatively about Method. London: Sage Publications.

Hodson, M., S. Marvin, B. Robinson and M. Swilling. 2012. Reshaping Urban Infrastructure: Material Flow Analysis and Transition Analysis in an Urban Context. Journal of Industrial Ecology 16(6): 789-800.

Hommels, A. 2005. Unbuilding Cities - Obduracy in Urban Sociotechnical Change. Cambridge, MA: MIT Press.

Hughes, T.P. 1983. Networks of Power: Electrification in Western Society 1880-1930. Baltimore: Johns Hopkins University Press.

Kapur, A. and T.E. Graedel. 2006. Copper mines above and below the ground. Environmental Science and Technology 40: 3135-3141.

Kennedy, C., S. Pincetl and P. Bunje. 2011. The study of urban metabolism and its applications to urban planning and design. Environmental Pollution 159: 1965-1973.

Lane, R. 2014. Understanding the Dynamic Character of Value in Recycling Metals from Australia. Resources 3: 416-431.

Law, J. 1991. Introduction: monster, machines and sociotechnical relations. In Law, J. (ed.). A Sociology of Monsters: Essays of Power, Technology and Domination. London: Routledge.

Minx, J., F. Creutzig, V. Medinger, T. Ziegler, A. Owen and G. Baiocchi. 2011. Developing a pragmatic approach to assess urban metabolism in Europe: A report to the European Environment Agency. Stockholm: Stockholm Environment Institute \& Technische Universität Berlin. 
Monstadt, J. 2009. Conceptualizing the political ecology of urban infrastructures: insights from technology and urban studies. Environment and Planning A 41: 1924-1942.

Moss, T. 2003. Utilities, land-use change, and urban development: brownfield sites as 'cold spots' of infrastructure networks in Berlin. Environment and Planning A 35: 511-529.

Moss, T. 2008. "Cold spots" of Urban Infrastructure: "Shrinking" Processes in Eastern Germany and the Modern Infrastructure Ideal. International Journal of Urban and Regional Research 32(2): 436-451.

Müller, D. 2009. Stock dynamics for forecasting material flows - Case study for housing in The Netherlands. Ecological Economics 59(1): 142156.

Nakamura, E., and K. Sato. 2011. Managing the scarcity of critical elements. Nature Materials 10: 158-161.

Naumann, M., and M. Bernt. 2009. When the tap stays dry: water networks in eastern Germany. Local Environment 14(5): 461-471.

Newman, P. 1999. Sustainability and cities: extending the metabolism model. Landscape and Urban Planning 44: 219-226.

Otter, C. 2010. Locating Matter: The Place of Materiality in Urban History. In Joyce, P., and T. Bennett (eds.). Material Powers: Culture Studies, History and the Material Turn. Chippenham: Routledge.

Ramaswami, A., C. Weible, D. Main, T. Heikkila, S. Siddiki, A. Duvall, A. Pattison and M. Bernhard. 2012. A Social-Ecological-Infrastructural Systems Framework for Interdisciplinary Study of Sustainable City Systems: An Integrative Curriculum Across Seven Major Disciplines. Journal of Industrial Ecology 16(6): 801-813.

Sismondo, S. 2004. An Introduction to Science and Technology Studies. Oxford: Blackwell.

Star, S.L. 1999. The Ethnography of Infrastructure. American Behavioral Scientist 43(3): 377-391.

Star, S.L. 2010. This is Not a Boundary Object: Reflections on the Origin of a Concept. Science, Technology \& Human Values 35: 601-617.

Star, S.L. and J. Griesemer. 1989. Institutional Ecology, "Translations" and Boundary Objects: Amateurs and Professionals in Berkeley's Museum of Vertebrate Zoology, 1907-39. Social Studies of Science 19: 387-420. 
Swyngedouw, E. 2006. Circulations and metabolisms: (Hybrid) Natures and (Cyborg) Cities. Science as Culture 15(2): 105-121.

Sörme, L., B. Bergbäck and U. Lohm. 2001. Century Perspective of Heavy Metal Use in Urban Areas: A Case Study in Stockholm. Water, air \& soil pollution 1(3-4): 197-211.

Tanikawa, H., S. Hashimoto and Y. Moriguchi. 2002. Estimation of Material Stock in Urban Civil Infrastructures and Buildings for the Prediction of Waste Generation. Proceedings from The Fifth International Conference on Ecobalance. pp. 803-806.

Tanikawa, H., T. Sakamoto, S. Hashimoto and Y. Moriguchi. 2004. Visualization of Regional Material Flow using Over-flow Potential Maps. Proceedings from The Sixth International Conference on Ecobalance. pp. 567-570.

Tanikawa, H. and S. Hashimoto. 2009a. Urban Stock over time: spatial material stock analysis using 4D-GIS. Building Research \& Information 37(5-6): 483-502.

Tanikawa, H., R. Inazu, S. Hashimoto and S. Kaneko. 2009b. Estimation of historical/spatial changes in subsurface Material Stock related to the construction sector of urban areas in Japan. Proceedings from International conference on hydrological changes and management from headwaters to the ocean. pp. 591-598.

Tarr, J.A. and G. Dupuy. 1988. Technology and the Rise of the Networked City in Europe and America. Philadelphia: Temple University Press.

Wallsten, B. 2013. Underneath Norrköping: An Urban Mine of Hibernating Infrastructure. Linköping: Linköping University Electronic Press.

Wallsten, B., A. Carlsson, P. Frändegård, J. Krook, S. Svanström. 2013a. To Prospect an Urban Mine: Assessing the Metal Recovery Potential of Infrastructure 'Cold Spots' in Norrköping, Sweden. Journal of Cleaner Production 55: 103-111.

Wallsten, B., N. Johansson and J. Krook. 2013b. A Cable Laid Is a Cable Played: On the Hibernation Logic Behind Urban Infrastructure Mines. Journal of Urban Technology 20(3): 85-103.

van Beers, D. and T.E. Graedel. 2003 The magnitude and spatial distribution of in-use copper in Cape Town. South African Journal of Science 99: 61-69. 
van Beers, D. and T.E. Graedel. 2007. Spatial characterisation of multilevel in-use copper and zinc stocks in Australia. Journal of Cleaner Production 15(8-9): 849-861.

van der Voet, E., J.B. Guinée and H. A. Udo de Haes. 2000. Heavy metals: A problem solved? Methods and models to evaluate policy strategies for heavy metals. Dordrecht: Kluwer Academic Press.

Weber, H. and D. Salehabadi. 2012. Unmaking Technologies: The Afterlife of Discarded Artifacts and Systems. Call for Papers: "Unmaking Technologies” Panel, Society for the History of Technology (SHOT) Annual Meeting, (Copenhagen, Denmark) 4-7 October 2012.

Zeltner, C., H-P. Bader, R. Scheidegger and P. Baccini. 1999. Sustainable metal management exemplified by copper in the USA. Regional Environ Change 1: 31-45.

\section{About the author}

Björn Wallsten is a PhD Candidate at the Environmental Technology and Management group, Linköping University, Sweden. He is an appointed Member of The Swedish National Committee for History of Technology and Science.

The author declares no conflict of interest. 